\title{
HACIA LA RECUPERACIÓN DE UNTEMA OLVIDADO: LA FÁBULA NEOCLÁSICA HISPANOAMERICANA (CON UNOS EJEMPLOS MEXICANOS)
}

\author{
Antonio Lorente Medina \\ UNED
}

\begin{abstract}
Resumen: Este artículo consta de dos partes: la primera presenta el estado actual de los conocimientos acerca de la "fábula neoclásica" hispanoamericana; la segunda analiza la obra de tres fabulistas mexicanos que corresponden a tres momentos distintos de la época de emancipación. A través de su ejemplo, se pretende mostrar la evolución de la "fábula neoclásica" mexicana, como hipótesis de trabajo extrapolable a los demás países de América Latina, desde formas y temas clásicos hasta el logro de fábulas originales, con temas adaptados a la realidad mexicana, como el las tensiones socio-políticas de la Guerra de la Independencia.
\end{abstract}

Palabras clave: fábula neoclásica, situación, recuperación, estado, independencia, guerra, insurgentes, realistas.

Abstract: This article consists of two parts: the first one presents the state of actual knowledges on the Spanish American "neoclassical fable"; the second one analyzes the works of three Mexican fabulists corresponding to three distinct moments of the period of emancipation. With their example, the article pretends to show the evolution of the Mexican "neoclassical fable", as an hypothesis of work exportable to other countries of Latin America, from classical forms and subjects to the achievement of original fables, with issues that are related to the Mexican reality, such as socio-political tensions in the Independence War. Keywords: fábula neoclásica, situation, recovery, state, independence, war, insurgents, realists.

En cuanto que se realiza un recorrido por los distintos manuales de literatura hispanoamericana existentes en el mercado editorial se impone un hecho con rotundidad: el olvido de la crítica mundial sobre la fábula literaria neoclásica, un subgénero literario que floreció con intensidad en las postrimerías del siglo XVIII y en las primeras décadas de la centuria siguiente ${ }^{1}$. Esta omisión

${ }^{1}$ La excepción, quizá, la constituya el manual de L. A. Sánchez, Historia comparada de las literaturas americanas. 2. Del naturalismo neoclásico al naturalismo romántico, vol. 2, Buenos Aires, 
se mantiene también en la bibliografía específica dedicada a la literatura hispanoamericana de la Independencia, como muestra la conocida antología denominada Poesía de la Independencia, que se publicara en la Biblioteca Ayacucho durante el año de 1979. En su estudio introductor el antólogo sólo dedica a la fábula un brevísimo párrafo, dentro del apartado "Temas: precisiones", en el que reconoce sin más explicaciones la importancia de la fábula neoclásica en la poesía de la independencia americana. El párrafo es el siguiente:

En un lugar especial, por filiación y por las conexiones que es necesario establecer, la fábula. Su aporte es igualmente nítido (cf. Navarrete, García Goyena, Lizardi, Melgar, Azcuénaga, fray Cayetano Rodríguez, Mora, español y americano, Pérez De Vargas, Bello y otros)22.

En consonancia con el exiguo espacio que le concede en su "Introducción", sólo recoge dos fábulas políticas en el corpus poético que nos presenta: "Los animales congregados en Cortes”, de García Goyena3; y "El buey de carga”, de Vargas Tejada, de los más de sesenta poemas recopilados, algunos tan esenciales como el canto a "La Victoria de Junín" o "La Agricultura de la Zona Tórrida". Parco bagaje para un subgénero que se reconoce fundamental en la poesía de este período. Desde luego, el peso excesivo que Carilla asigna a algunos escritores, prácticamente desconocidos, en detrimento de fabulistas eximios como Domingo de Azcuénaga, Melgar o Fernández de Lizardi, posiblemente se deba a que el crítico argentino incide más en la poesía hispanoamericana de la Independencia que en la poesía hispanoamericana durante la Independencia, muy próximo todavía al espíritu que inspiró La Lira Argentina (1824) o El Parnaso Oriental (1835)4.

En principio, podría pensarse que la carencia de estudios dedicados al tema se derivaría de la práctica inexistencia de fábulas y de fabulistas durante el período emancipador, pese a las numerosas indicaciones que afirman lo contrario, como la expresada por González Urbina en su "Estudio Preliminar" a la Antologia del Centenario (1910) ${ }^{5}$, cuando subraya el cambio operado en la poesía mexi-

Editorial Losada, 1973, 220-222, que le dedica un breve apartado, por otra parte disparatado en su deriva hacia un mestizaje supranacionalista, como cuando afirma sin ninguna base documental que "allí donde hubo mayor caudal de sangre indígena, floreció también mejor el fabulismo"(220).

2 E. Carilla, Poesía hispanoamericana de la Independencia, Caracas, Fundación Mariscal de Ayacucho, 1979, XXVII. Lo curioso es que a la hora de publicarlos en su antología se olvide de seleccionarlos.

3 R. García Goyena, Fábulas, Guatemala, Biblioteca Guatemalteca de Cultura Popular "15 de septiembre" (vol. 89), 1965, 163-172.

4 Esta última colección recoge excepcionalmente una fábula de Doña Petrona Rosende, "La Cotorra y los Patos" (t. II, 1835, 175-176), en que responde a los ataques de los hombres a las mujeres, ignorando sus propios defectos, similares o peores a los de ellas.

5 L. González Urbina, "Estudio Preliminar", en Antología del Centenario. Estudio documentado de la literatura mexicana durante el primer siglo de Independencia, México, Imprenta de Manuel León Sánchez, 1910, CCV: "Cruzan las sátiras como venenosas y sutiles dardos de alusión: cruzan las pasiones, los rencores, las esperanzas con su disfraz de frivolidad y de risa (...) Son mañosas, 
cana desde el estallido revolucionario, en que desaparecen las poesías amatorias y bucólicas - "la poesía desmedrada y pulida de los melendistas y moratinianos", dice él- y su lugar lo ocupan las fábulas, los epigramas y la poesía satírica, "empobreciendo el caudal poético de El Diario de México a partir de 1811”. Pero en cuanto que se penetra en la poesía de la época surgen numerosos hombres de letras que cultivaron la poesía didáctica en la forma de las fábulas. Es cierto que en muchos casos sólo sabemos su nombre, o que sólo nos ha llegado copiada alguna fábula suya en una colección posterior y sin ninguna seguridad sobre su atribución. Pero también lo es que ello se debe fundamentalmente a que la inmensa mayoría de la poesía hispanoamericana de la Independencia se publicó en periódicos como La Gazeta de México, El Diario de México, El Despertador Americano El Semanario Patriótico, El Pensador Mexicano, La Gaceta de Guatemala, La Aurora de Chile, La Gazeta de Buenos Aires, El Patriota de Venezuela, o el Mercurio Venezolano, cuyo contenido está por recoger y estudiar. Carecemos no ya de ediciones facsimilares o digitalizadas, sino en muchos casos de simples catálogos y de índices orientativos ${ }^{6}$.

En 1987 Boyd G. Carter ${ }^{7}$ denunciaba la situación de precariedad en que se encontraba la poesía hispanoamericana del siglo XIX como consecuencia de que casi todos los autores publicaron sus versos en periódicos y revistas, para concluir afirmando, basándose en el estudio que Malcolm D. Mc Lean realizó sobre diez autores mexicanos en El Siglo Diez y Nueve (1841-1896), que todavía el $83 \%$ de la obra literaria de esos autores permanece desconocida. Si esta afirmación es cierta, mucho más lo es en el caso de la poesía de la Independencia, especialmente con la poesía de fábulas, letrillas y epigramas, que por su singular condición satírica se escribieron muchas veces en hojas volanderas, manuscritas o impresas, o en pasquines y fueron férreamente perseguidas por las autoridades virreinales ${ }^{8}$ (o por los patriotas insurgentes, en los sitios en que éstos dominaban).

hipócritas, mal intencionadas y traviesas. El género apológico es un arma de manejo difícil de gran utilidad en las luchas arteras de la política”.

6 Para que nos hagamos una idea del inmenso caudal literario que nos perdemos - y ciñéndonos sólo al tema que no ocupa, la fábula neoclásica - sirva este ejemplo: el libro de R. Wold, $E l$ Diario de México, primer cotidiano de Nueva España (Madrid, Editorial Gredos, 1970, 29) reseñó ciento ochenta fábulas en la primera etapa del Diario de México (1805-1812), aunque en general sólo nos dijo el número del periódico en que se encuentra, a veces completado con el nombre del autor. Una simple extrapolación analógica nos permite intuir lo que aún no conocemos. En 2002 E. Martínez Luna realizó un índice onomástico del Diario de México en esta primera época: Estudio e indice onomástico del Diario de México. Primera época (1805-1812), México, UNAM, Instituto de Investigaciones Filológicas, 2002.

7 B. G. Carter, "Revistas literarias hispanoamericanas", en Historia de la Literatura Hispanoamericana. Tomo II. Del neoclasicismo al modernismo, coord. L. Íñigo Madrigal, Madrid, Ediciones Cátedra, 1987, 75-86. Para este punto concreto, 75-76.

8 Como muestra sirva este botón: la carta reservada que el virrey Calleja envió a Fernando VII el 18 de agosto de 1814, en la que le daba cuenta del extraordinario desarrollo que adquirió el 
Afortunadamente veinte años después de la Independencia de la América Hispana (con la excepción de las Antillas mayores), Juan María Gutiérrez publica su América Poética $(1846)^{9}$, una recopilación antológica de la poesía hispanoamericana de la primera mitad del siglo XIX marcada por la amplitud de miras y la ambición literaria que caracteriza toda su obra. En su afán por mostrar "que en el pensamiento americano hai elevación, nobleza y unidad" y pese a subrayar que durante la emancipación sólo se dio una poesía guerrera, Gutiérrez recoge veintitrés fábulas literarias: doce de García Goyena (249-260); cuatro de Martínez de Navarrete (608-610); y siete de Real de Azúa (722-726), convirtiéndose así su compilación en el repertorio de fábulas neoclásicas más importante hasta la aparición del libro de Mireya Camurati un siglo y cuarto después. Parecía que con La fábula en Hispanoamérica ${ }^{10}$ el estudio de la fábula neoclásica hispanoamericana iniciaba definitivamente el camino de su recuperación. Por fin aparecía un libro que se dedicaba monográficamente al análisis de la fábula literaria y completaba su investigación con una amplia antología de fabulistas pertenecientes a cada uno de los países del continente hispanoamericano. $\mathrm{El}$ avance fue, sin duda, significativo, porque por primera vez se nos ofrecía a los críticos la posibilidad de indagar sobre casi un centenar de escritores que, o eran fabulistas, o habían incursionado en alguna ocasión en este subgénero.

Es cierto que en cuanto que se analiza el trabajo de Camurati, se descubren sus limitaciones. Un libro de estas características propendía a ser necesariamente superficial. No es el momento de señalar sus limitaciones. Bástenos subrayar la primera y más importante de ellas: sus pretensiones totalizadoras. No se compadece la intención de abarcar un tema tan amplio como la fábula literaria desde los tiempos precolombinos hasta autores contemporáneos a la autora en el tiempo en que se redactaba el libro con el escaso número de páginas que dedica a su explicación. Así, por citar algunos ejemplos, despacha en las veinte páginas del capítulo segundo "las peculiaridades de la fábula hispanoamericana", junto con las primeras referencias a la llegada de fabulistas europeos a América, los modelos literarios que operan sobre ella y una propuesta (sin desarrollar luego en el libro) sobre la especificidad de la fábula hispanoamericana, basada en "la forma en que el fabulista incorpora o utiliza estos materiales", en la perfecta caracterización del personaje "como tipo", y en que del contexto se desprenda "una visión auténtica de la realidad americana" (35). Como vemos, tres postulados bastante subjetivos como para encontrar alguien que sea capaz

periodismo en México tras la promulgación de la libertad de imprenta por las Cortes de Cádiz, y la proliferación de papeles sediciosos por todo el país, que le llevaron a suprimirla de nuevo. Recogida por González Urbina, op. cit., CLVII.

9 J. M. Gutiérrez, América Poética, parte lírica: colección escojida de composiciones en verso escritas por americanos en el presente siglo, Valparaíso, Imprenta del Mercurio, 1846. Las páginas harán referencia a esta edición.

10 M. Camurati, La fábula en Hispanoamérica, México, UNAM, 1978. Todas las citas hacen referencia a este año. 
de establecer inobjetablemente axiomas como el de "una visión auténtica de la realidad americana"11. Y lo mismo podemos decir del capítulo tercero, donde en menos de treinta páginas se nos pretende consignar los problemas sociales y políticos que atañeron a toda la sociedad hispanoamericana — diecinueve paísespor espacio de quinientos años.

En cualquier caso, su capítulo cuarto, "Los fabulistas hispanoamericanos", constituye la aportación principal de Camurati. Recopila en él los datos biográficos y bibliográficos de alrededor de un centenar de fabulistas hispanoamericanos (treinta y nueve de los cuales dentro del período neoclásico) con una ordenación alfabética por países y, dentro de ellos, más o menos cronológica. Concentra aquí brevemente numerosas noticias desperdigadas y las integra en una unidad libresca, con cierto grado de homogeneidad. Es cierto que en ocasiones omite la fuente de información en que se basa para transmitir dichos datos, y que por lo general rehúye la consulta directa de las fuentes originales y las primeras ediciones de los autores (muchas veces, las únicas ediciones existentes). Lo normal es que se apoye en estudios anteriores o en antologías nacionales de relevancia, que recogen algunos ejemplos de las fábulas que luego ella edita. Pero también lo es que por vez primera se ofrece al lector y al estudioso un corpus significativo de fabulistas hispanoamericanos, que abre perspectivas insospechadas para seguir indagando en esta dirección.

Lamentablemente la crítica mundial ha desestimado las posibilidades que ofrecía el libro de Camurati y ha relegado el estudio de este subgénero literario y sólo podemos encontrar datos específicos sobre la obra fabulística de algunos escritores hispanoamericanos en los escasos trabajos introductorios de los que han tenido la fortuna de ser reeditados, cual es el caso de García Goyena, Fernández de Lizardi, Melgar, o recientemente José Ignacio Basurto, o escasas referencias a la fábula literaria neoclásica, engastadas en estudios más amplios sobre determinados autores concretos ${ }^{12}$. La realidad es que a estas alturas del si-

11 Por si fuera poco todo esto, dedica siete de las veinte páginas del capítulo a la fábula indígena, no obstante reconocer al principio su nula o escasa repercusión en la fábula literaria hispanoamericana: "Si aplicamos un criterio riguroso, debemos excluir a la fábula indígena de este estudio (...) por la razón elemental de que aquélla no ha sido escrita en español, sino en las lenguas nativas y, en la mayoría de los casos, antes de la llegada del conquistador europeo" (38; las cursivas son mías). Por otra parte y como simple curiosidad, me gustaría saber cuántas fábulas indígenas se pudieron escribir en sus lenguas nativas "antes de la llegada del conquistador europeo".

12 Yo mismo he caído en este pecado, como cuando estudié la obra inédita de Mejía Lequerica y analicé sus Fábulas literarias (A. Lorente Medina, "Impronta neoclásica y realidad americana en la desconocida obra poética de José Mejía Lequerica”, en Italia, Iberia y El Nuevo Mundo. Presencias culturales italianas e ibéricas en el Nuevo Mundo, ed. C. Camplani, M. Sánchez y Spinato, Roma, Bulzoni Editore, 1997, 219-231. Especialmente 227-231), o cuando compilé el CD de poesía virreinal para la colección "Clásicos Tavera" (Textos clásicos de Poesía Virreinal, Madrid, Fundación Histórica Tavera, 2001), donde debería de haber dedicado un apartado de mi introducción a la fábula neoclásica y tendría que haber introducido un corpus mínimo de fabulistas hispanoamericanos. 
glo XXI (2011) poco o nada se ha adelantado sobre la fábula neoclásica hispanoamericana desde el estado crítico en que la dejó la estudiosa argentina hace treinta y tres años. Las páginas que ofrezco a continuación, dedicadas a tres fabulistas mexicanos prácticamente desconocidos, pretenden entregar unas breves reflexiones con el fin de contribuir mínimamente a la recuperación del tema en un país como México, donde tanto proliferó la fábula literaria, con la esperanza de que este esbozo de trabajo anime a estudiosos posteriores.

Hasta donde se me alcanza, cronológicamente ostenta la primacía como fabulista en México don José Agustín de Castro (1730-1814), natural de Valladolid, hoy Morelia. Por Francisco Pimentel sabemos que fue colaborador de $L a$ Gaceta y de El Diario de México ${ }^{13}$ y que en 1797 publicó dos volúmenes de poesías sagradas y humanas en la ciudad de Puebla. El segundo volumen, titulado Miscelánea de poesias humanas ${ }^{14}$, es un conjunto abigarrado de poemas laudatorios de circunstancias (a Carlos IV, a los fastos de la ciudad de Puebla, al virrey, al aniversario del obispo de Puebla), poemas pastoriles y filosóficos, rococós, o jocosos ("Al casamiento de una vieja", o "Descripción de un celoso" ambos en décimas), cuatro diálogos poéticos jocosos entre una marquesa y su criada, entre un abogado y un practicante, y dos para dos críticos que están paseando, dos embriones de sainetes —o "pitipiezas", como los denomina Castro-: Los Remendones, pieza teatral situada en el barrio de San Pablo de la ciudad de México; y El Charro, un "juguetillo nuevo" situado en la ciudad de Puebla (ambos con lenguaje coloquial y deformaciones fonéticas propias del lenguaje del "payo" (131-150 y 150-158). Y catorce "fabulillas" que constituyen en estos momentos motivo de nuestra atención.

Se observa en ellas el predominio del verso octosílabo, especialmente del romance (nueve de las catorce composiciones), en su forma tradicional, con rima aguda en los versos pares ("Los charros" y "La ciega casada"), o con una conclusión de heptasílabos y pentasílabos, como es el caso de la fábula "El pintor". No obstante hay una ligera tendencia a la polimetría, manifestada en el uso de pentasílabos hexasílabos, heptasílabos, y endecasílabos y la seguidilla ("El satírico"), la oda heptasilábica ("La imprenta"), la anacreóntica ("E1 mono y el perro") y los sáficos de "La casa deteriorada". En cualquier caso, todas sus composiciones, a excepción de "La casa deteriorada", utilizan formas ligeras, como corresponde al tratamiento liviano de los asuntos que Castro trata en ellas.

13 F. Pimentel, Historia crítica de la poesía en México, México, Oficina Tipográfica de la Secretaría de Fomento, 1892, 476-477.

14 J. A. Castro, Miscelánea de poesías humanas, vol. 2, Puebla, Oficina de D. Pedro de la Rosa, 1797. Ejemplar de la BNM, signatura 3/33691. Todas las citas las haré por este ejemplar. En la BNM hay otros dos títulos de Joseph Agustín de Castro que muestran las formas propias de su Miscelánea de poesías sagradas (1797): Sentimientos de la América... dolorida en la...muerte del... Conde de Gálvez, su Vir[r]ey..., México, Don Felipe de Zúñiga y Ontiveros, 1786; y El triunfo del silencio: canción heroica que al glorioso Martirio del inclito... San Juan Nepomuceno decía..., México, Don Felipe de Zúñiga y Ontiveros, 1786. 
Sus temas no presentan ninguna novedad; son tópicos de la fábula neoclásica $y$, como ocurre en ella, tienen la finalidad horaciana de divertir educando ${ }^{15}$. Siete tienen que ver con la poesía y con el mundo de los escritores, quizá recordando las que Iriarte había escrito unos años antes. En sus fábulas "El satírico" y "El poeta fingido" Castro arremete contra los malos o los falsos poetas, por su falta de mordacidad o por ser meros compradores de poemas, que luego dan como suyos. A los plagiarios, o a los falsos eruditos ("los eruditos a la violeta") destina "La imprenta" y "El pintor". Y tampoco se olvida de las rencillas que motiva la vanidad de los poetas por su anhelo de trascender en la fábula "La Pluma y el Fusil", donde enfatiza los tiros que se dan los escritores entre ellos,

Pues con el anhelo loco

de hacerse de mucha fama, por el cañón de la Pluma no es menos lo que disparan (181).

Las siete restantes escarnecen la vanidad humana, las violentas reacciones de los hombres cuando se emborrachan, la mentira, la ruindad y la miseria humana, sin que falten las tradicionales burlas a las mujeres por su fragilidad moral y su coquetería ("La ciega casada"), o por su ridiculez cuando, ya viejas, se obstinan en componerse el rostro con afeites ("La casa deteriorada"), porque siempre sobresale "el deterioro de la antigua finca/ sobre la mezcla" (191).

En "El tabernero", el personaje de la historia que da nombre a la primera de sus fábulas se erige en portavoz del escritor para equiparar las cualidades que se atribuyen a ciertos animales, de acuerdo con la descripción de Baldecebro (dominico español que había residido en México en el siglo XVII), con las de los hombres, para mostrar cómo éstos superan a los primeros en sus rasgos bestiales cuando se embriagan: al tigre en la furia, al loro en la incontinencia verbal, al buey en los cuernos que lo adornan, al elefante en su "deformidad" (la trompa). Concluye la fábula con la ambigua afirmación de que todos los hombres prefieren a la zorra, aunando semánticamente en este sustantivo los significados disímiles de 'animal astuto' y de 'borrachera':

$\mathrm{Y}$ aunque las varias especies

de animales los asombran, lo más seguro es que quedan aturdidos con la zorra (166).

15 No encuentro en sus fábulas nada de las "costumbres mexicanas", que dijera Pimentel y repitiera Camurati, si exceptuamos la dedicada a "Los charros", en la que Castro pretende básicamente remedar la "aparente sandez" de su parla, aunque el español que utiliza sea académico. Quizá en la alusión a Baldecebro pueda haber un vago eco del mundo cultural mexicano, que a mi entender remite, en último extremo a Buffon (que utiliza al dominico en su ensayo) y a la polémica sobre la degeneración de las especies en América. 
En esta fábula apreciamos dos rasgos característicos de las fábulas de José Agustín de Castro: la mayor parte de sus personajes son seres humanos (ocho), en algún caso combinados con objetos inanimados (el estudiante y las letras de molde en "La imprenta"); y en ocasiones la moraleja no se desprende del texto de la fábula como lección moral, sino que concluye el tono festivo en que ésta está escrita. En este sentido, sus "fabulillas" guardan cierto parentesco con los diálogos poéticos y las petipiezas del volumen. Con todo, en la mayoría, la moraleja constituye una llamada al lector que se desprende como lección moral del núcleo de la fábula, bien sea a través de autor (como en "La casa deteriorada", en "los dos ruines" o "en el poeta fingido") y son las más, o bien por intervención de alguno de los personajes que interviene en la fábula. En el caso de "Los charros", el tercero de ellos; en el de "El satírico", el amigo zaherido; y las letras de molde en el caso de la "La imprenta". Pero siempre con un prosaísmo ramplón y un aire jocoso, que Castro establece en su primera fábula y no abandona hasta el cierre de las mismas ("El hospital de locos"). Precisamente en esta fábula, compuesta en esdrújulos para provocar a risa, el autor, consciente de ello y tras fustigar a los locos quiméricos del siglo sin $\mathrm{cura}^{16}$ en su moraleja, deja al lector libertad absoluta para que enmiende los defectos de sus versos, como vemos en este fragmento:
Parece que lo satírico puesto en esdrújulo métrico, demanda por lo lacónico, se le supla lo patético[.] Mas si algo falta, pregúntenlo; si aún está con pluma, pélenlo; si hay un pie quebrado, apúntenlo; y si el poeta amarga, enmiélenlo (192).

Cinco años después de la publicación de Miscelánea de poesias bumanas aparecen en México las Fábulas morales (1802)17 de José Ignacio Basurto, por aquel entonces sacerdote asistente en la parroquia del pueblo de indios de San Francisco Chamacuero, del Obispado de Michoacán. Hasta hace muy poco se ignoraba cualquier dato sobre la biografía y el perfil del autor. Pimentel sólo recogió el hecho de que Basurto no fuera citado por Beristáin y que él no había podido ver las Fábulas morales, aunque por noticias que le habían allegado sus próximos concluyera que eran "apenas de mediano mérito"18. Mireya Camurati, en

16 Así reza su moraleja: "Así hay no pocos Heráclitos, / que con un tesón quimérico/ lloran al siglo sin lúcidos/ quando son ellos los frenéticos" (192).

17 En México, Imprenta de la Calle de Santo Domingo y esquina de Tacuba, Año 1802. Utilizo la edición de C. Cerrillo, R. Cerda González y D. Tanck de Estrada, Cuenca, Ediciones de la Universidad de Castilla La Mancha, 2009. En adelante todas las citas las haré por esta edición.

18 Pimentel, op. cit., 479. 
su estudio de 1978, lo situó, basándose en lo dicho por José Toribio Medina y en la Antología del Centenario, a finales del siglo XVIII y comienzos del siglo XIX, y destacó de las fábulas, que tampoco había leído, "la sencillez, la originalidad de algunos asuntos, el color local que el autor sabe imprimirles y la correcta versificación" ${ }^{19}$. Y Rebeca Cerda nos aclaró en 2009 que Basurto era natural de Salvatierra, una zona según Florescano de gran crecimiento económico y alto número de criollos, que concentraba "los focos más avanzados de renovación intelectual" hasta el punto de que unos años después se convirtió en "la matriz de la insurrección" de México ${ }^{20}$. En la actualidad la web del gobierno de Guanajuato nos ofrece una breve semblanza biográfica, que constituye la información más completa y la base de los datos que ofrecemos a continuación. Por ella sabemos que José Ignacio Basurto nació en Salvatierra el 5 de abril de 1755 y que en dicho lugar empezó sus estudios hasta que, con la protección de Don José Javier de Rivera, marchó a Morelia (antes Valladolid) para continuar estudios en el Real y Primitivo Colegio de San Nicolás. Allí transcurrió gran parte de su vida estudiantil y de maestro, coincidiendo en diversas ocasiones con el Padre Hidalgo en el claustro de dicho colegio. Conocido como extraordinario orador sagrado y fino literato, fue ordenado presbítero en 1780, aunque continuó su labor magistral en Morelia. Para 1802 lo encontramos como sacerdote asistente en la parroquia del pueblo de indios de San Francisco Chamacuero. Y en 1805 accedió como titular al curato de Salvatierra, donde continuó hasta su muerte el 28 de enero de 1810.

En el "Prólogo" de sus Fábulas morales Basurto subraya la originalidad de sus fábulas, llegando a afirmar que sus "argumentos son aborto de mi fantasía" (43). Y coinciden en ello los tres editores recientes de su libro. Sin negar lo que puede haber de cierto en estas aserciones y a expensas de volver más adelante sobre ellas, hemos de apuntar, a renglón seguido, que la presencia de Iriarte y Samaniego es constante en la obra del ilustrado mexicano. Se percibe con claridad en la intencionalidad que concede a la variedad métrica utilizada y en la exigencia de destreza técnica que Basurto se plantea para componer sus fábulas. La figura de Samaniego se impone de manera especial en la composición del "Prólogo" al lector. El paralelismo de las ideas manifestadas por Basurto con las desarrolladas por Samaniego en 1781 es evidente. Ambos destacan en sus prólogos la finalidad educativa que los mueve; en el caso de Samaniego, destinada a los jóvenes del Real Seminario Vascongado; y en el caso de Basurto, a los niños de "las escuelas de primeras letras" de San Francisco Chamacuero, si bien el último las escribe "por llenar con algún ejercicio de utilidad y diversión" el tiempo libre que le deja su empleo, y el primero lo haga instado por el director de la "Real

19 Camurati, op. cit., 112.

20 R. Cerda González, "La obra de Basurto. Una puesta en común de antiguos saberes y nuevas ideas", en J. I. Basurto, Fábulas morales, Cuenca, Ediciones de la Universidad de Castilla La Mancha, 2009, ed. cit., 107-126. Para este punto concreto, 125. 
Sociedad Vascongada". Los dos se esfuerzan por "hacer versos fáciles hasta acomodarlos a la comprensión de los muchachos" 21 . Los dos reciben muestras del entusiasmo de sus alumnos; y los dos sienten recelo ante el juicio de los sabios y grandes fabulistas, por temor a que encuentren sus fábulas "desregladas", "sin gracia ni chiste" en la narración y atentatorias contra las leyes de la Fábula ${ }^{22}$. En este sentido, la mayor originalidad del prólogo de Basurto estriba en la clara preocupación que muestra porque los niños abandonen "los Cuentos de $\mathrm{Pe}$ dro Urdimalas, el Príncipe Lagarto y otras innumerables fruslerías" (43), que los mantienen embelesados y los divierten inútilmente, y se inicien en la poesía didáctica de las fábulas y, de rechazo, en la literatura. Incluso desecha su miedo a que los niños no pudieran penetrar la moraleja de sus historias, pensando en que los adultos se las explicarían y en el beneficio que obtendrían de ello unos y otros.

Como podemos ver, Basurto, como buen escritor ilustrado, tiene siempre muy presente el precepto horaciano de deleitar aprovechando y está en contra de los cuentos y consejas populares, que aterrorizaban a los niños o los entretenían, pero de los que no podían sacar una lección provechosa. Lo advertimos en toda su obra fabulística y lo especifica con claridad en el prólogo y en el apóstrofe inicial con que abre su fábula primera, titulada significativamente "El Perico a los niños de las escuelas":

\author{
Inocentes Niños \\ a quienes encantan \\ inútiles cuentos \\ e insulsas patrañas: \\ En mis Fabulitas \\ mi amor os regala \\ de gusto y provecho \\ la sabrosa vianda. \\ Al paladar vuestro \\ será acomodada. \\ Si insípida al gusto \\ de la gente sabia (45).
}

21 F. M. Samaniego, Fábulas, Madrid, Ediciones Cátedra, 1997,153-157. Para este punto concreto, 155. Ya cayó en ello el autor del "Parecer" de las Fábulas morales, Ramón Fernández, cuando destacó de ellas su "versificación fácil y corriente".

22 Es cierto que el temor a no conseguir la variedad del metro, la naturalidad y la sencillez, la gracia del estilo y la exacta observancia de la reglas de la Fábula, se convirtió en un recurso literario frecuente en los fabulistas, como muestra, por citar, entre otros muchos ejemplos, J. J. Fernández de Lizardi, en el prólogo de sus Fábulas de El Pensador Mexicano (1817), donde justifica la pobreza de sus fábulas basándose en sus nulas dotes para realizar esta labor y recordando que el propio Samaniego, que sí tenía talento para escribir fábulas con estas cualidades, desconfiaba de poder acertar en lo que escribía. Ver J. J. Fernández de Lizardi, Obras. I. Poesias. Fabulas, México, UNAM, 1963, 285. 
Esta fábula, con su oposición entre gente instruida y niños, representados simbólicamente en el perico "charlatán", los pajaritos y el loro, de un lado; y las humildes "hormiguitas", de otro, nos ofrece las pautas para interpretar todo el libro como un decálogo educativo destinado a los niños. De hecho, su estructura externa presenta una forma simétrica con apóstrofe inicial, núcleo narrativo de la fábula y moraleja final, que surge cuando Basurto ha elaborado sus fábulas y piensa presentarlas a "la gente instruida", pero teme su rechazo. Su mensaje final se relaciona, como no podía ser de otro modo, con el desarrollo de la acción fabulística, pero también con el apóstrofe inicial y con el prólogo a los lectores, confiriéndole gran coherencia semántica. Observémoslo a continuación:

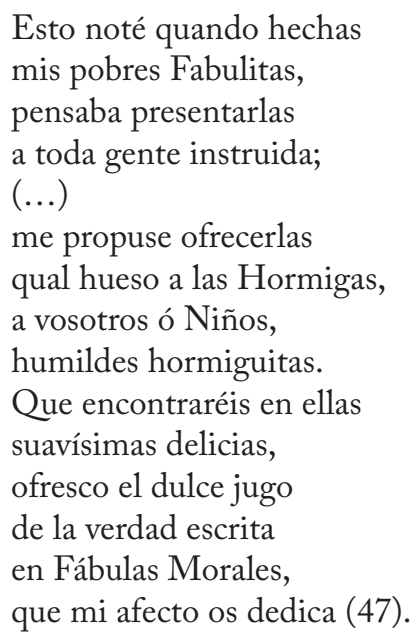

La preocupación de Basurto por la educación moral infantil se refleja en todas y en cada una de sus fábulas. Algunas de ellas versan sobre las nefastas consecuencias que acarrea una madre excesivamente permisiva ("La aguililla y el pollo" y "Las torcasas"), o sobre la necesidad de castigar al desobediente ("La gallina y el pollo"). Otras cargan contra los petimetres o currutacos desocupados, preocupados en demasía por la moda y afeminados en suma, porque brindan a los ingenuos niños un mal ejemplo que los puede arrastrar hacia el vicio. Como es bien sabido, es éste un tema muy recurrente en la literatura ilustrada a un lado y otro del Atlántico. En México la sátira al currutaco constituía un lugar común en la crítica de tipos y costumbres. Se le pintaba como un ser ocioso e inútil, falto de carácter y superficial, atento exclusivamente a su atuendo y a su forma de actuar, alejada de la hombría tradicional. Wold, en su estudio sobre El Diario de México ${ }^{23}$, recoge los diversos ataques de que fue objeto el personaje en las páginas del períodico. Otro buen ejemplo lo compone el extenso poema satírico El currutaco por alambique, poema satírico-burlesco de Manuel Gómez

23 Wold, op. cit., 121-127. Para su versión femenina (“currutacas” y "pirradas”), 127-131. 
Marín, publicado en 179924 , en el que aparece el currutaco como el resultado de la cocción que un grupo de diablos hace en el infierno con el fin de expandir por el mundo cuanta maldad quepa en un caldero ardiente. El influjo de Quevedo y la proximidad del poema con los Caprichos de Goya, no impide que disfrutemos de la aparición del "hermafrodita muñequito", con los mismos rasgos que utilizará el fabulista mexicano, quien sin duda lo conocía, puesto que el poema fue publicado en la misma editorial mexicana que sus obras:

De hembra el cuerpo parece, pero el alma es de macho, $y$ bien merece

llamarse hermafrodita, aquel que siendo macho a la hembra imita.

Las fábulas en que Basurto satiriza este tipo "ejemplar" son "Las abejas, joven y vieja", "El petimetre, el sabio y el mono" y "El pájaro y los ganzos". La última en concreto recoge los tópicos con que se le zahería por su extravagancia en el vestir, su estupidez y su afeminamiento. La anécdota nos muestra un pájaro zancudo que, "haciendo ostentación de su buen gusto y garvo", se presenta a los gansos con un vestido extraño e impropio de un ave: patas forradas con plumaje blanco; calzones "en extremo ajustados"; cola con dos cañones largos; faldillas de un "especial casaco"; y sombrero ridículo en el copete. Al verlo así se ríen las demás aves. Él, molesto, les tacha de rústicos y groseros, y les aclara que es un currutaco. La extrañeza del nombre, junto con la ridiculez de su traje produce mayor hilaridad en los circunstantes, que lo motejan de "patarato"; con lo que el zancudo se retira muerto de vergüenza. Pero no contento con ello, el autor enfatiza en la moraleja el escarnio de su figura hasta afirmar que "vilmente se afemina”, como parecía sugerir lo insólito de su vestido ${ }^{25}$. Dice así:

Aquel que a lo que es moda

se entrega sin reparo,

y quando mueve a risa, se considera guapo,

que ridículo afecta

la acción el gesto, el paso,

24 M. Gómez Marín, El currutaco por alambique, México, Talleres de Don Joseph de Zúñiga y Ontiveros, 1799. Hay un breve y útil estudio sobre este poema en B. López de Mariscal, "El currutaco por alambique de Manuel Gómez Marín. Un texto satírico del siglo XVIII”, en Poesía satírica y burlesca en la Hispanoamérica colonial, ed. I Arellano y A. Lorente Medina, Madrid-Frankfurt am Main, Iberoamericana-Vervuert, 239-252.

25 Las referencias a sus patas forradas con plumaje blanco, tienen que ver con el atuendo mañanero de las damas de la clase alta mexicana, en los que el color blanco sobresalía por encima de cualquier otro color: su vestido era de batista blanca; la "túnica de olán" de algodón blanco; zapatos blancos de tacón alto con cintas y tiras del mismo color; guantes por lo general blancos; y sombrero de paja blanco. Pero también tienen que ver con las críticas al afeminamiento de los currutacos, que para algunos iba a llevar a una confusión en los trajes de hombres y de mujeres. 
vilmente se afemina;

y quando el pobre ufano

creyéndose muy digno

de atención, pide aplausos,

díganle quanto gusten;

mas no le digan $\operatorname{sabio}^{26}(91)$.

Las máximas y virtudes que encierran sus restantes fábulas constituyen un buen complemento a los estudios que realizaban los niños mexicanos de aquellos años, cuyos fundamentos esenciales eran la cartilla, el catecismo y el catón ("las tres ces", como se las llamó); un compendio de alfabetización precaria, educación cristiana y lectura de frases cortas para apuntalar la lectura infantil. Por otra parte, no debemos olvidar que, si ilustrado, Basurto era también y sobre todo sacerdote y, como tal, autor de un Devocionario para celebrar (...) el felicisimo Tránsito del (...) B. Sebastián de Aparicio (1795 y 1796) y de un Quinario en honor del Dulcísimo Nombre de María...(1800) ${ }^{27}$. No es extraño por esto que varias fábulas suyas censuren diversos pecados capitales, como la ira ("El gallo y los cuervos"), la avaricia ("Las hormigas buxilera, y arriera"), la pereza ("Las torcasas"), y muy especialmente, la soberbia. Basurto toca la cuestión de la soberbia en distintas fábulas. En "El perico a los niños de las escuelas" contrasta la soberbia del perico "charlatán", que desprecia el hueso, con la humildad de los niñoshormigas y del propio autor. La luciérnaga representa a las numerosas personas "que siendo de unas luces muy escasas, / los llega a dominar la rara idea/ de imaginar sus brillos superiores/ a los que por los suyos son Estrellas", como prudentemente refiere el ratón al grillo en "La luciérnaga, el grillo y el ratón". Incluso la araña de "La araña y el grillo", engreída porque con su tela hace "gran presa de los insectillos", cae en ese pecado, aunque la realidad posterior la haga ver su error. Pero es en la fábula que cierra el fabulario, "La araña y la tejedora", donde se manifiesta en todo su esplendor. La anécdota se sitúa en un "locus amoenus" campestre: una tejedora mexicana — posiblemente india — canta plácidamente mientras teje una delicada tela, hasta que es interrumpida por una "araña arrogante" que elogia su propia tela hasta el punto de considerar que no hay tejedor en el mundo que pueda igualarla. La tejedora se ríe de las pretensiones de la araña y ridiculiza su tela y a cuantos la siguen:

Y el que en tus producciones, y vanidad te imita

26 La amonestación final del autor para que llamen al currutaco de todo menos sabio, guarda relación invertida con la fábula 22a "El petimetre, el sabio y el mono". No la vamos a desarrollar, pero sí señalarla al menos.

27 Publicados, según J.T.Medina (La Imprenta en México (1536-1821), t. VI, Santiago de Chile, Imprenta Casa del Autor, 1911, 14, 48 y 124) en la imprenta de Mariano Zúñiga de Ontiveros. 
merece como tú

los elogios de la risa (105).

Cualquier lector atento puede advertir que, bajo la aparente sencillez de la trama, Basurto actualiza y adapta el mito clásico de Aracne, la famosa tejedora que, ensoberbecida por sus obras, negó a la propia Atenea su magisterio y sufrió por su arrogancia a vivir convertida en araña y a poder tejer sólo las telas de este animal. Lo interesante del caso es que Basurto ha despojado su fábula de elementos míticos y nos la ha presentado como una escena campestre mexicana, con su tejedora "atada al tronco de un granado hermoso". Además, ha aprovechado el motivo (¿hay ecos de "El gusano de seda y la araña", de Iriarte?) para finalizar su libro de fábulas incluyendo una moraleja final que lo engloba totalmente bajo la virtud de la humildad, que se convierte en el ejemplo que los niños han de seguir y en la norma de conducta del propio escritor, muy en consonancia con lo que había expresado en el prólogo y en la moraleja de la primera de las fábulas:

Para que a ejemplo suyo,

quando mis pobres Fábulas concluyo

jamás hagan mis labios

temiendo la sonrisa de los sabios (106).

No rehúsa Basurto aprovechar la literatura paremiológica en la composición de sus fábulas, posiblemente porque quería ofrecer ejemplos extraídos de la cultura popular conocidos por sus pequeños destinatarios. Así, en "El caballo y el buey" se basa en el famoso refrán "Ver la paja en el ojo ajeno y no ver la viga en el propio" para reprender a quienes critican permanentemente los defectos de los demás ignorando los suyos propios; en la ardilla de la fábula $5^{\text {a }}$, que imprudente abandona la "frondosa milpa" próxima a su casa "por mejorar su suerte", escenifica el refrán "Más vale pájaro en mano que ciento volando"; y la enseñanza que se desprende de "Los perros" remite a la sentencia "Ir por lana y salir trasquilado", como explicita el último verso de su moraleja: "en pos de lana, y buelven trasquilados". Tampoco olvida prevenirnos contra la falsa amistad ("El rústico"), ni contra aduladores o amigos por interés, como muestran "El gato con la bolsa" y "La aveja, araña y mosca". Avisa de los peligros de la imprudencia temeraria en "El pajarillo preso", de los fanfarrones con fama de valientes ("El alacrán, araña y mosca"), e incluso de la pasión amorosa, que ciega a quien la tiene como la culebra de "La culebra y el sapo".

Cierra Basurto su decálogo educativo con dos fábulas en las que nos previene de los problemas que se derivan de las aspiraciones nobiliarias o puestos relevantes en quienes han nacido ricos o han adquirido bienestar con su trabajo. Era ésta una pretensión muy frecuente en el mundo hispano, donde los prejuicios de hidalguía todavía consideraban deshonroso el trabajo, que los ilustrados atacaron con vigor y que no podía faltar en Basurto. En México (y en España) había 
mucha gente que malograba su vida y sus negocios en busca de quiméricas recomendaciones que le ofrecían ascender socialmente con la obtención de títulos nobiliarios y, en muchos casos, caían en manos de desaprensivos que los esquilmaban cruelmente. El mensaje de Basurto es claro al respecto: hay que huir de ambiciones ilusorias, "abandonar la altura y bajar al suelo", como afirma en "Las palomas", y refugiarse en la virtud y en la dignificación por el trabajo. De lo contrario cualquiera puede llegar a convertirse en el hazmerreír de los demás, como le ocurre al caballo de la fábula 7a ("El caballo y el asno"), porque

El que bajo ha nacido,
y logra el esplendor de la riqueza,
no pretenda atrevido
hazer ostentación de la Nobleza,
que puede algún Borrico
decirle eres vil aunque mui Rico (62).

Los personajes que pueblan sus fábulas son, en su inmensa mayoría, animales desposeídos de sus características físicas o parafísicas ${ }^{28}$, caracterizados psicológicamente como paradigmas del comportamiento humano: abejas, palomas, gallinas, gallos, ratones, hormigas, arañas, grillos, luciérnagas, caballos, asnos, bueyes y aves variadas que nos ofrecen con sus actuaciones modelos de conducta para seguir o rechazar. En este sentido, Basurto sigue el modelo fabulístico moderno, establecido por La Fontaine y Samaniego. Pero se separa de ellos en su clara intención de elegir animales domésticos o integrados en el ambiente rural en el que enmarca sus fábulas, desechando animales salvajes o exóticos (tigres, lobos, zorros, cocodrilos, leones, camellos u osos). Incluso los escasos seres humanos que intervienen pertenecen al mundo aldeano (el rústico y el aldeano) o a profesiones relacionadas con él, cual es el caso del artesano que se dedica al beneficio de la plata, que se nos describe en la fábula 7a ("El rústico"), con la sola excepción de "El petimetre, el sabio y el mono", mucho más clásica y convencional que el resto. Como vemos, ejemplos todos del mundo circundante que rodeaba a los niños a quienes iban dirigidas las fábulas y a quienes se pretende enseñar. Un espacio pleno de lugares amenos y apetecibles, un paisaje humanizado, donde encontramos "lugares de rosas", "cornisas de puertas", "frondosas milpas", casas, huertas y árboles tupidos plantados por el hombre - granados, pinos, fresnos- que Basurto procura incardinar en su tierra natal, como muestran los ejemplos desperdigados en la historia de sus fábulas, en que hace mención a su patria chica, Salvatierra, y al molino "La Esperanza". A eso responden también, a nuestro juicio, las explicaciones sobre las hormigas buxileras, o la

28 Sigo la clasificación establecida por E. Palacios Fernández, "La caracterización de los personajes en las Fábulas de Samaniego", Boletín de la Institución Sancho el Sabio, XVI, 1972, 169 189, que volvió a recoger después en Vida y obra de Samaniego, Biblioteca Alavesa "Luis de Ajuria", Caja Municipal de Ahorros, 1975, 183 y siguientes. 
aclaración del significado del sustantivo 'gorguz', con una acepción diferente de la usual en España ("hierro de la garrocha”), que recoge Francisco Santamaría en su Diccionario de Mexicanismos ${ }^{29}$.

En esto consiste la originalidad de sus fábulas, que se incrementa con la utilización de formas diversas para desarrollar sus moralejas sin caer en la monotonía de la repetición. Al hilo de esta afirmación quizá convenga señalar el deliberado equilibrio que Basurto lleva a cabo en la composición de sus moralejas, unas veces a través del narrador-autor y otras con la intervención de los animales que integran la fábula. En el primer caso, el narrador-autor puede extraer del propio asunto la moraleja, pero con frecuencia aparece como testigo fiel de los hechos, bien interpelando a alguno de los animales que han intervenido, como en el caso de "Las palomas", o bien recordando lo dicho por éstos, como en el caso de "El hortelano y las hormigas" o de "La araña y el grillo". En el segundo caso, los propios animales ofrecen su moraleja por lo general después de haber sufrido en sus carnes las consecuencias de los males señalados en la fábula. Así, la ardilla de la fábula $5^{\mathrm{a}}$ a los holgazanes que deambulan por los caminos, o la torcaza mal criada de la fábula $16^{a}$ a los apáticos de vida muelle y apoltronada. Posiblemente el más acabado ejemplo de moraleja elaborada literariamente esté en la fábula 14a ("la aguililla y su pollo"), donde la madre aguililla, desconsolada por la muerte de su cría, se arranca una pluma para que el autor escriba la enseñanza que ella misma le dicta:

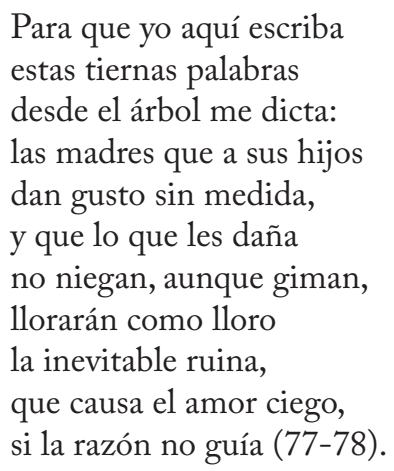

Como hemos podido ver por los ejemplos de los fabulistas anteriores, la fábula neoclásica mexicana - y por posible analogía la del resto de Hispanoamérica- fustiga vicios y defectos morales o sociales que los autores perciben en la sociedad de su tiempo con el ánimo de corregirlos. Pero a partir de cierto momento, y coincidiendo con los movimientos emancipadores derivó hacia la sátira política de forma similar a como ocurrió también en España a partir de la Guerra de Independencia. Es lo que ocurre en las Fabulas Politicas y Militares

29 F. Santamaría, Diccionario de Mexicanismos, Méjico, Editorial Porrúa, 1974. 
de Ludovico Lato Monte, pseudónimo que encubre al escritor Luis de Mendizábal ${ }^{30}$.

Henríquez Ureña colocó al frente de la entrada que le dedicó en la Antología del Centenario ${ }^{31}$ una semblanza biográfica, que extractada resumió Mireya Camurati y que nosotros seguimos también. Nacido en San Luis Potosí a finales del siglo XVIII, estudió en el Colegio de San Ildefonso de México, del que llegó a ser vicerrector. Se doctoró en Teología por la Universidad de México. En 1809 opositó a la plaza de canónigo doctor de la catedral de Puebla, como se desprende del documento allegado por Amaya Garritz en 199032. Unos años después (1816) ingresó en los jesuitas, ocupando el cargo de rector del Colegio de San Pablo (Puebla), hasta que tras la segunda expulsión de la Orden de México (1821) tuvo que abandonarla. Colaboró en el Diario de México, bajo diversos pseudónimos, como era frecuente en la época: Manuel de Blasidiz, Lucas Simol de Lato-Monte (latinización del vasco 'Mendizábal') y Ludovico Lato-Monte. Sus Fabulas Politicas y Militares reflejan las tensiones políticas y sociales que anegaron a la sociedad mexicana de la segunda década del siglo XIX en su paso de vasallos del rey de España a ciudadanos de una nueva nación independiente, bajo la regencia provisional de Iturbide, que considera todavía a Fernando VII el garante de la estabilidad del sistema ${ }^{33}$, aunque esté muy próxima a romper amarras con el monarca español. Constituyen un conjunto homogéneo y cerrado, deliberadamente preparado por el autor para presentarse a sí mismo como un personaje independiente, al margen de las banderías y tiranteces que la incertidumbre de la situación política del momento provocaba en gran parte de la población. A eso responde sin duda la estrecha relación existente entre la "Advertencia" que coloca al comienzo del libro, la composición de la fábula "E1 Mochuelo", que le sirve de "prólogo" y la fábula decimosexta, "Esopo entre ladrones y alguaciles", con que lo cierra. Desde luego, no es casual que Mendizábal flan-

30 L. de Mendizábal y Zubialdea, Poesias Varias Y Fabulas Politicas Y Militares de Ludovico Lato-Monte (1821). Utilizo la edición facsimilar de Kessinger Publishing, 2011. Todas las citas serán de esta edición.

31 P. Henríquez Ureña, 1910, 253-256. Ya J. M. de Beristáin y Souza (1817), recogió algunos datos biobibliográficos del autor (Biblioteca Hispano Americana Septentrional, Amecameca, Tipografía del Colegio Católico, 1883,258), como su lugar de origen, sus estudios en el Colegio de San Ildefonso, "rector del eximio de San Pablo de la Puebla de los Ángeles", doctor de esta universidad, o autor del "Poema Guadalupano en forma de idilio análogo a las ocurrencias de la Insurrección causada por el Cura Hidalgo, Impreso en México por Arizpe, 1811, 40". Lo recoge A. Garritz, Impresos novohispanos (1808-1821), t. I, México, UNAM, Instituto de Investigaciones Históricas, 1990, 259.

32 Garritz, ibid., 120: Relación de méritos y ejercicios literarios del Dr. Luis de Mendizábal y Zubeldea como opositor a la canongía doctoral de la catedral de Puebla de los Ángeles, 18 de marzo de 1809.

33 Esto es lo que parece reflejar su Catecismo de la Independencia en siete declaraciones por Ludovico Lato-Monte(...), 1821, tanto en su dedicatoria a Iturbide, de momento "Presidente de la Regencia Gobernadora del Imperio Mexicano", como cuando, al tratar de las formas de gobierno, señala "el monárquico como el más conveniente para todos los pueblos". Ver Garritz, ibid., t. II, 1057. 
quee sus fábulas entre el epígrafe inicial de Fedro y la aparición de Esopo en la última fábula. En su afán de acogerse a la tradición clásica de mayor solera percibimos la intención de distanciarse de las circunstancias que las habían provocado. ¿Pero qué circunstancias fueron éstas?

En la "Advertencia" Mendizábal nos informa de la fecha en que compuso sus fábulas -1815- de las razones por las que las escribió (como "pasatiempo" ante "el grave destino que servía") y del abandono de las mismas por dedicarse a otras ocupaciones "más graves". Estas razones y "la escasez de sus luces" le impidieron componer nuevas fábulas o corregir las ya escritas que, por otra parte, nunca pensó publicar. Así es que dejó que circularan copias de las mismas para deleite de sus amigos, sin preocuparse de las consecuencias que le podía acarrear, hasta que de pronto vio publicadas en un periódico de Puebla algunas de sus fábulas, "desfiguradas" o acomodadas "a la época presente lo que se dijo en otra muy diversa” (4). Ante la certeza de que el tal periodista ${ }^{34} \mathrm{iba}$ a seguir publicándolas, desestimando la idea de pulirlas o de aclarar que dichas fábulas correspondían a un momento histórico diferente y en la seguridad de que podían ser mal interpretadas, se decidió a imprimirlas seis años después y sin tiempo para poderlas corregir, como hubiera deseado y como se merecía el público lector.

Es evidente que Mendizábal con la impresión de su libro sale al paso de la posible agresión del periódico y del periodista innominados para evitar que sus fábulas fueran tergiversadas. Es muy probable que ésta fuera la razón por la que situó su obra fabulística dentro de la perspectiva clásica a que aludimos antes y por la que reiteró en la fábula prologal los mismos argumentos que había expuesto en su "Advertencia”. Para realizar dicha fábula Mendizábal se inspiró en la fábula LXI de Iriarte, "El sapo y el mochuelo"35. De ella tomó el asunto, los personajes que intervienen, el metro y la rima (decasílabos y hexasílabos que riman en asonante sus versos pares y sus versos impares). Sólo que en la fábula de Iriarte el mochuelo reprende en el sapo a los escritores que publican cuanto componen sin el más mínimo escrúpulo, mientras que en la fábula de Mendizábal el mochuelo se ve obligado a salir del tronco del árbol en que pasa sus días escondido para defenderse de las calumnias del sapo ante el senado que ha congregado éste, aceptando su fealdad pero demostrando a los demás que no es tan monstruoso como lo ha pintado su antagonista. O lo que es igual, que Mendizábal que también se siente calumniado como el mochuelo, se ve obligado a publicar sus fábulas como son, pero no adulteradas:

Estos versos que al público saco de faltas van llenos;

34 Ignoramos a qué periódico y a qué periodista se refiere Mendizábal, aunque bien podrían ser La Abeja Poblana y Juan Nepomuceno Troncoso, como insinúa Pedro Henríquez Ureña en su semblanza biográfica.

35 T. de Iriarte, Poesías, Madrid, Espasa- Calpe, Clásicos Castellanos, 1963, 82. 
pero que otros abulten el cargo

sufrirlo no debo (6).

Los asuntos de sus fábulas remiten claramente a un clima de guerra civil, con sus secuelas de odio, muerte, destrucción, saqueos indiscriminados, enfrentamientos cainitas entre criollos y europeos, y un alto grado de militarización en la sociedad mexicana, de efectos indeseables muchas veces. En la fábula inicial, titulada "Los animales en Cortes", escrita en ovillejos de heptasílabos y endecasílabos, advertimos un eco evidente de las expectativas y zozobras que generó en el mundo hispano la promulgación de la Constitución de 1812 por las Cortes de Cádiz. No es el momento de precisar la repercusión que la primera constitución española tuvo en el desarrollo de las libertades de América. Bástenos recordar en esta ocasión que títulos similares o idénticos a la fábula de Mendizábal circularon con profusión por el continente americano hasta el punto de que durante mucho tiempo la crítica confundió esta fábula con otras análogas, como "Los animales congregados en Cortes", de Rafael García Goyena, y que fue Pedro Henríquez Ureña quien alertó sobre este error tan extendido ${ }^{36}$. En el caso concreto de México y de la fábula de Mendizábal, "Los animales en Cortes”, quizá convenga destacar dos hechos que pueden estar en la base de su composición. El primero de ellos tiene que ver con la promulgación por Morelos de la Constitución de Apatzingán el 22 de octubre de 1814. Dicha constitución, editada con el título de Decreto Constitucional para la libertad de la América Mexicana, se basaba en la Constitución de Cádiz, abolía la esclavitud y el sistema de castas, y en su artículo 19 establecía que la ley debía ser igual para todos. Es verdad que no pudo casi ponerse en práctica porque Morelos fue hecho prisionero por las fuerzas realistas en noviembre de 1815 y fusilado un mes después, con lo que la insurrección quedó descabezada y a punto de fenecer. Así es que la incorporación de la ciudad de Zacatula en la fábula con que finaliza su libro Mendizábal no me parece casual, y menos con el sentido de penal de los insurrectos en oposición al penal de Ceuta. Fue precisamente en Zacatula donde se refugió Morelos tras sufrir varias derrotas de las fuerzas de Calleja y comenzó la redacción de la Constitución de Apatzingán. En este sentido, la primera versión de la fábula de Mendizábal bien podría suponer una contestación a la Constitución aprobada por los rebeldes surianos. El segundo de ellos tiene que ver con al versión definitiva de "Los animales en Cortes". Fue el siguiente: en 1820, un año antes de la publicación de las Fábulas Políticas y Militares, apareció en Puebla y en México una "Fábula Política, los animales en Cortes", publicada por un tal J. N. T. (Juan Nepomuceno Troncoso), cuyo tema con toda seguridad coincidía con el desarrollado por Mendizábal - la igualdad política de todos los hombres ante la ley- aunque muy probablemente con mensaje opuesto, como parecen reflejar el nombre de la imprenta poblana en que se editó ("Imprenta Liberal") y la

36 P. Henríquez Ureña, op. cit., 253-256. 
métrica utilizada (silva, con sus connotaciones de métrica bastante libre, frente a pareados $)^{37}$. Si nuestra conjetura es cierta, y tiene ciertos visos de serlo, Troncoso aprovechó la fábula escrita unos años antes por Mendizábal para sostener, desde una perspectiva liberal e independentista, la igualdad de todos los hombres, como decía la Constitución de 1812 y reiteraba la Constitución de Apatzingán, invalidando el mensaje escrito por éste en 1815. Mendizábal, al ver su fábula arteramente "acomodada a la época presente" y "desfigurada" en su contenido, se sintió aludido y percibió la necesidad de publicarla sin corrupciones con el fin de evitar posibles suspicacias políticas.

$\mathrm{Su}$ argumento, bastante previsible, presenta al león en su tradicional papel de rey de los animales que, urgido por las múltiples quejas de sus vasallos, decide convocar a Cortes a todos, a razón de tres diputados por especie animal. El tono irónico y escéptico del autor-narrador preside los diversos momentos de la narración: la llegada de los distintos animales de acuerdo con las cualidades físicas con que los ha caracterizado la fábula clásica ("el fiero tigre", "el toro ardiente", "el jaco belicoso", "el noble elefante", "el vil insecto"); el despliegue de elocuencia de los diversos discursos; los debates estériles ante la imposibilidad de acuerdos; la propuesta del gallo extranjero ${ }^{38}$ sobre la bondad de votar la igualdad ante la ley; y la aprobación final de la propuesta, elevada al rango de decreto "por interés los unos/ por zánganos los otros y por tunos" (10). El rey firma el decreto y concluye el congreso entre grandes aplausos. Pero en la salida el ratón ve que el gato, su enemigo, lo mira con ademán severo y "aún uñas tiene,/ y predominio sobre mí mantiene" (11). El rey le responde que ningún decreto puede eliminar de un plumazo los dones que a cada uno "al nacer le dio naturaleza", y decide posponer la puesta en práctica del nuevo decreto "hasta que sea pensado/ el negocio, y mi reino nivelado", manteniendo las viejas leyes conformes con las leyes de la Naturaleza:

Por hoy mantenga el Toro sus dos cuernos:

el Mulo sus pesuñas,

el Tigre y Gato sus filosas uñas,

guarde el Lobo sus dientes

y cada uno sus armas diferentes (11).

Como podemos ver, Mendizábal está contestando a los partidarios de la igualdad de los hombres ante la ley promulgada por la Constitución de 1812 y

37 Garritz, op. cit., t. II, 902.

38 ¿Hay un ataque indirecto de Mendizábal al afrancesamiento de las costumbres y las leyes hispanas en la aparición de este personaje? No sería extraño. El hecho de que sea un gallo -animal que simboliza a Francia- y además extranjero, quien presenta la propuesta y que ésta se apruebe por unanimidad, pese a que inicialmente hasta el burro "se llegó a sonreír", porque como recrimina Mendizábal, “...un extranjero/ pasa en cualquiera junta por primero”, nos hace pensar seriamente en ello. 
proponiendo mantener las leyes de "l'Ancien Régime" que sostenía la Monarquía Hispana, basándose en que Dios y la Naturaleza sancionaban las diferencias existentes entre todos los seres y parecían justificar con esas diferencias la desigualdad de trato ante la ley. De ahí que concluya su moraleja con los siguientes versos:

Ningún legislador, aunque profundo, podrá igualar al Mundo, donde a cada creatura dio carácter distinto la natura.

Siempre al cobarde mandará el valiente, y el que es trabajador al indolente: siempre la palma cederá rendido el pobre al rico, el necio al entendido (11-12).

Ésta es la visión política que se desprende del pensamiento de Mendizábal. Visión que entraba en conflicto con la de los que propugnaban la emancipación de México y la supremacía del poder político sobre los caudillos militares, como Agustín de Iturbide, en estos momentos Presidente de la Regencia Gobernadora del Imperio Mexicano. Para Mendizábal en cambio, el ejército, y con él sus jefes (fueran europeos o caudillos insurgentes) constituye un elemento de orden que repercute en beneficio de toda la sociedad. De ahí que salga al paso de quienes alzan sus voces en contra de los excesos cometidos por los soldados en los lugares por donde pasan en su fábula "La criada y el ratón", replicando que los soldados, como el gato de la fábula, constituyen el mal menor en épocas de inestabilidad como la que vivían en 1815, "pues malos como son estos señores/ hacen morir a sabandijas peores” (45). La presencia del ejército es constante en sus fábulas, aunque en muchas ocasiones sea para criticar los aspectos negativos de la tropa. Así, unas veces censura la conducta de ciertos soldados que aprovechan la guerra para conseguir beneficios ilícitos, frutos del pillaje, como en la fábula "El gavilán y los dos gallos", donde opone la figura del rufián y ladrón al soldado que busca gloria y honor. Otras, zahiere al militar cobarde, que se ceba con el enemigo que huye y evita al que se le enfrenta, como ocurre en "Los dos galgos", o condena a los ejércitos improvisados y anárquicos, en los que abundan los jefes, pero no los soldados, porque todos se creen con derecho a mandar y que, como "Los muchachos" de la fábula $15^{\mathrm{a}} \mathrm{o}$ las avutardas de la fábula $6^{\mathrm{a}}$, huyen despavoridos y en desbandada a la primera acometida del enemigo. Pero por encima de todo Mendizábal siente la anarquía y el desgobierno de su patria como una desdicha que acarrea dolor y pobreza a sus gentes, como se percibe en "La gata y el loro" o en "Los conejos y las liebres". El ansia desenfrenada de libertad y la idea de fácil enriquecimiento prevalecen por encima de cualquier otra consideración y son las causantes de la mortandad de sus compatriotas y de 
la devastación que sufre México. No es extraño que concluya la segunda de las fábulas con esta dolorosa moraleja:

Éste ya es el quinto año

del figurado bien y cierto daño.

¡Grave dolor, tristísima memoria!

Otros apliquen la fingida historia (29).

En la fábula 13a, "Perros y gatos", Mendizábal sitúa el origen de esta tragedia en el enfrentamiento entre paisanos y europeos, que —según él— surge cuando se exaltan los lazos de paisanaje hasta la exasperación en contra de los lazos de parentesco que unían a criollos y peninsulares. A partir de este momento el lugar de nacimiento y la vecindad se erigen en señas de identidad superiores a las originadas por las relaciones familiares. Los paisanos se hermanan en contra de los nacidos fuera de México y la animadversión recíproca degenera en un conflicto tan absurdo para Mendizábal como demoledor para el bienestar del país. Por él los sacerdotes abandonan su labor pastoral y abrazan la lucha armada, como relata la fábula "El cordero lobo"39; cunden los desalmados que se aprovechan de su situación para robar impunemente, protegidos por la inmunidad del uniforme (el gavilán de "El gavilán y los dos gallos"); y aparecen los chaqueteros, que sacan ventajas de ambos bandos, como muestra el avestruz que da nombre a la fábula $8^{a}$. Mendizábal avisa a sus compatriotas de los peligros que pueden resultar de esa guerra cainita que enfrenta a "brutos y aves" - criollos y europeos-: la destrucción del bienestar por mor de dirimir quiénes tienen que dirigir la sociedad novohispana ("Las dos gallinas"); o lo que es peor, la posibilidad de que un tercero (otra potencia extranjera europea) se aproveche de la lucha entre Murat y Dupon ${ }^{40}$, "grandes perros de un solo amo", como dice en "Los dos perros y el mico", para alzarse con el santo y la seña del "pedazo de jamón" que ambos disputan, del mismo modo que el mico de la fábula:

Novo-Hispanos[:] ¿Qué, no os pesa

de un reñir tan crudo y fiero?

Advertid que si no cesa, asomándose un tercero, perderéis toda la presa (36).

39 La alusión a los sacerdotes que, como Hidalgo y Morelos, se erigen en líderes de una revolución popular, que luego no pueden mantener dentro de unos cauces ordenados, no puede ser más evidente. También es claro que Mendizábal retoma invertida la expresión "el lobo disfrazado de cordero" para componer su fábula. No resulta tan indiscutible el posible influjo de la fábula de Iriarte "La mona".

40 El nombre de los dos perros "del mismo amo" remite inmediatamente a los mariscales franceses homónimos. Es clara la intención de parodiarlos por parte de Mendizábal: el uso de tratamientos franceses (Sieur, para Murat) o la jerga con que se expresa Dupon en francés macarrónico ("mon ami" ce ne est plat") así lo manifiestan. 
Tampoco se libran de sus dardos los españoles europeos. En su equidistancia política, marcada por la moderación de su carácter, Mendizábal ataca irónicamente a los españoles porque afrentan a los criollos mexicanos sin advertir que, al denigrarlos, se ofenden a sí mismos, ya que son sus progenitores. La fábula en que recoge esta sátira, "El asno, el caballo y el mulo", es archiconocida desde que fuera impresa en la Antología del Centenario. Reproduce en quintillas la conversación que sostienen el caballo y el asno mientras pacen amigablemente "por una misma heredad". Durante ella los dos équidos van desgranando alternativamente las malas artes del macho, un ser "coceador", "bellaco" e "infecundo", incapaz de sacar las virtudes de sus padres: no es bello ni valiente como el caballo, ni humilde, candoroso y paciente como el asno. El mulo, corrido de oírlos, les avergüenza haciéndoles caer en la cuenta de que ellos son los culpables de su existencia y de los vicios que lo adornan. La extrapolación de las virtudes del caballo y del asno al español y al indio permite la identificación del criollo mexicano, mestizo como el macho, y el traspaso de los pecados del caballo a los europeos ${ }^{41}$ :
¿Con la agudeza del Macho
los otros no salen reos?
Pues, perdonad, Europeos, la fabulita os despacho.
Cuanto queráis sin empacho
del criollo decid ufanos,
decid de los megicanos
vicios, maldades y horrores;
pero ellos son, mis señores,
hechuras de vuestras manos (40-41).

Así las cosas, es bastante lógico que Mendizábal se viera en 1815 como el Esopo de su fábula 16a "Esopo entre ladrones y alguaciles", sometido a las críticas de realistas y de insurgentes. ¿Fue esto lo que realmente ocurrió y la razón por la que se vio en la necesidad de publicar sus fábulas, que circulaban manipuladas, en su estado original seis años después? No lo sabemos con certeza. Pero no parece muy descabellado pensarlo a la luz de los tercetos con que remata su fábula final, en los que la presencia de Zacatula y de Ceuta, encarnaciones respectivas de la represión insurgente o realista, imposibilita cualquier tipo de acuerdo entre las partes o que se persiga los "vicios" allá donde se encuentren:

Los que sin juicio me leyeren hoy,

a Zacatula quiénes me enviarán, quiénes a Ceuta en el primer convoy.

41 Lo curioso es que, siendo básicamente cierta la crítica, el autor se olvide del indio como uno de los dos componentes de la nacionalidad mexicana para cargar las tintas exclusivamente sobre una de las dos razas, posiblemente porque la segunda carecía a sus ojos de la fuerza política necesaria, o porque inconscientemente no la tuviera él mismo en consideración. 
Dejad, señores, vuestro doble afán:

ni soy chaqueta ${ }^{42}$, ni rebelde soy;

los vicios noto donde quiera están (48).

No queremos extendernos más. Los tres ejemplos expuestos muestran la evolución de la fábula neoclásica mexicana y las complejidades que su interpretación encierra, en un período decisivo para la historia de México, como para no percibir la necesidad de seguir haciendo calas similares en otros lugares de la América Hispana. En los tres fabulistas es constante la presencia de Iriarte y de Samaniego, así como el empleo de la polimetría de acuerdo con las directrices marcadas por ambos: mostrar las destrezas versificadoras del autor y evitar la monotonía que impone la repetición del mismo metro en las distintas fábulas. Pero si en un primer momento, con José Agustín de Castro predominan los formas clásicas de las fábulas sobre tema literario o sobre la reprensión de vicios tradicionales, con una ligera ambientación mexicana, en Basurto ya encontramos un intento deliberado de imprimir sabor local a sus Fábulas Morales con el fin readaptarlas a la realidad circundante de los niños indígenas a quienes van dirigidas. El esquema de conducta que se desprende de ellas se corresponde con el de un buen católico, contento con lo que le ha tocado vivir, conforme con lo que tiene y alejado de aspiraciones quiméricas, virtuoso trabajador y refractario a la moda. En una palabra, el modelo de Basurto propugna la formación de un buen campesino sedentario y enemigo de novedades y de la emigración azarosa. Años después la situación en México ha cambiado y Mendizábal nos ofrece un ideario distinto en sus Fabulas Politicas y Militares de Ludovico Lato-Monte. Escritas al fragor de la guerra civil emancipadora, Mendizábal se erige en portavoz de las indecisiones de un grupo de criollos mexicanos, compuesto por hacendados, comerciantes y miembros connotados de la Iglesia, temeroso de la deriva populista que iban tomando los movimientos insurgentes, representados aquí por Morelos, y de la intransigencia del bando realista (los "chaquetas"), que no admitía pensamiento divergente alguno ni más reformas que las que emanasen del Absolutismo Monárquico, recientemente restaurado por Fernando VII en España. Este grupo, “juicioso” y moderado como el autor se autodenomina, apoyó finalmente a Iturbide (1821) ante el recelo de que el triunfo de Riego reinstaurase en América la Constitución de 1812 y encauzó definitivamente a

42 Santamaría, op. cit., 361, aclara que "chaqueta" era el apodo con que eran conocidos, durante la guerra de insurrección y aun después, los partidarios de los españoles. Y L. González Obregón (México viejo. Noticias históricas, tradiciones, leyendas y costumbres, París-México, Librería de la Viuda de C. Bouret, 1900), en el capítulo que dedica a "E1 Parián", 393-442, nos amplía la siguiente noticia: "Los realistas o chaquetas, capitaneados por el español D. Gabriel de Yermo, se conjuraron, como es sabido, en contra del Virrey D. José de Iturrigaray, y lo depusieron del mando en la citada noche del 15 de Septiembre (...). El Parián fue, pues, el cuartel general de los chaquetas. Aun antes de la prisión del Virrey en 1808, se veía con prevención aquel mercado, como centro de las maquinaciones del partido realista" (402-403). 
su favor la creación de una nueva nación independiente. La edición de las $F a-$ bulas Politicas y Militares y la del Catecismo de la Independencia en 1821 (este último en la imprenta del Estado) son el mejor ejemplo de ello.

\section{BIBLIOGRAFÍA}

Basurto, J. I., Fábulas, ed. de P. C. Cerrillo, R. Cerda González y D. Tanck de Estrada, Cuenca, Ediciones de la Universidad de Castilla La Mancha, 2009.

Beristaín y Souza, J. M. de, Biblioteca Hispano Americana Septentrional, Amecameca, Tipografía del Colegio Católico, 1883.

Camurati, M., La fábula en Hispanoamérica, México, UNAM, 1978.

Carilla, E., Poesía hispanoamericana de la Independencia, Caracas, Fundación Mariscal de Ayacucho, 1979.

Carter, B. G., "Revistas literarias hispanoamericanas", en Historia de la Literatura Hispanoamericana. Tomo II. Del neoclasicismo al modernismo, coord. L. Íñigo Madrigal, Madrid, Ediciones Cátedra, 1987, 75-86.

Castro, J. A. de, Sentimientos de la América...dolorida en la ... muerte... del Conde de Gálvez, su Vir[r]ey..., México, Don Felipe de Zúniga y Ontiveros, 1786.

-, El triunfo del silencio: canción heroica que al glorioso Martirio del inclito... San Juan Nepomuceno decía..., México, Don Felipe de Zúñiga y Ontiveros, 1786.

—, Miscelánea de poesías humanas, Puebla, Oficina de D. Pedro de la Rosa, 1797.

Cerda González, R., “'La obra de Basurto. Una puesta en común de antiguos saberes y nuevas ideas"', en J. I. Basurto, Fábulas morales, Cuenca, Ediciones de la Universidad de Castilla La Mancha, 2009, 107-126.

Fernández Lizardi, J. J., Obras. I. Poesías. Fabulas, México, UNAM, 1963.

García Goyena, R., Fábulas, Guatemala, Biblioteca Guatemalteca de Cultura Popular "15 de septiembre" (vol. 89), 1965.

GarRitz, A., Impresos novohispanos (1808-1821), México, UNAM, Instituto de Investigaciones Históricas, 1990.

Gómez Marín, M., El currutaco por alambique, México, Talleres de Don Joseph de Zúñiga y Ontiveros, 1799.

González Obregón, L., México viejo. Noticias históricas, tradiciones, leyendas y costumbres, París-México, Librería de la Viuda de C. Bouret, 1900.

González Urbina, L., "Estudio Preliminar", en Antología del Centenario. Estudio documentado de la literatura mexicana durante el primer siglo de Independencia, México, Imprenta de Manuel León Sánchez, 1910.

Gutiérrez, J. Ma a América Poética, parte lírica: colección escojida de composiciones en verso escritas por americanos en el presente siglo, Valparaíso, Imprenta del Mercurio, 1846.

Iriarte, T. de, Poesías, Madrid, Espasa-Calpe, Clásicos Castellanos, 1963.

López de Mariscal, B., "El currutaco por alambique de Manuel Gómez Marín. Un texto satírico del siglo XVIII", en Poesía satírica y burlesca en la Hispanoamérica colonial, ed. I Arellano y A. Lorente Medina, Madrid-Frankfurt am Main, Iberoamericana-Vervuert, 239-252. 
Lorente Medina, A., "Impronta neoclásica y realidad americana en la desconocida obra poética de José Mejía Lequerica”, en Italia, Iberia y El Nuevo Mundo. Presencias culturales italianas e ibéricas en el Nuevo Mundo, ed. C. Camplani, M. Sánchez y P. Spinato, Roma, Bulzoni Editore, 1997, 219-231.

—, Textos clásicos de Poesía Virreinal, Madrid, Fundación Histórica Tavera, 2001.

Martínez Luna, E., Estudio e indice onomástico del Diario de México. Primera época (1805-1812), México, UNAM, Instituto de Investigaciones Filológicas, 2002.

Medina, J. T., La Imprenta en México (1536-1821), t. VI, Santiago de Chile, Imprenta Casa del Autor, 1911.

Mendizábal y Zubialdea, L. De, Poesias Varias Y Fabulas Politicas Y Militares de Ludovico Lato-Monte (1821), U. K., Kessiger Publishing, 2011.

Palacios Fernández, E. "La caracterización de los personajes en las Fábulas de Samaniego", Boletín de la Institución Sancho el Sabio, XVI, 1972, 169-189.

—, Vida y obra de Samaniego, Biblioteca Alavesa "Luis de Ajuria", Caja Municipal de Ahorros, 1975.

El Parnaso Oriental ó Guirnalda poética de la República Uruguaya, Buenos Aires, Imprenta de la Libertad, 1835.

Pimentel, F., Historia crítica de la poesía en México, México, Oficina Tipográfica de la Secretaría de Fomento, 1892.

Samaniego, F. Maa Fábulas, Madrid, Ediciones Cátedra, 1997.

Sánchez, L. A., Historia comparada de las literaturas americanas. 2. Del naturalismo neoclásico al naturalismo romántico, Buenos Aires, Editorial Losada, 1973.

Santamaría, F., Diccionario de Mexicanismos, Méjico, Editorial Porrúa, 1974.

Wold, R., El Diario de México, primer cotidiano de Nueva España, Madrid, Editorial Gredos, 1970. 